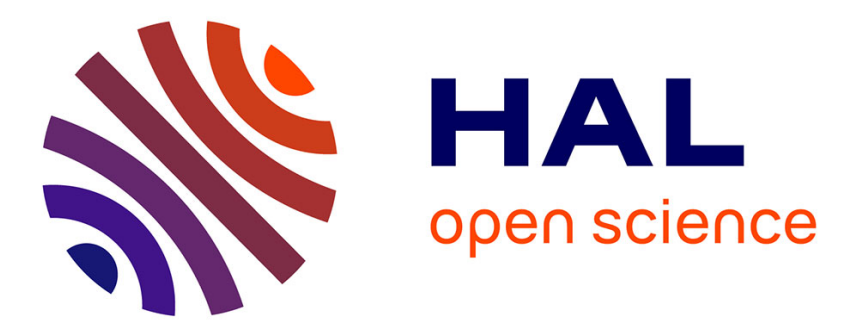

\title{
Visual exploration of reaching space during left and right arm movements in 6-month-old infants
}

F. Morange-Majoux, E. Devouche, C. Lemoine-Lardennois, E. Orriols

\section{To cite this version:}

F. Morange-Majoux, E. Devouche, C. Lemoine-Lardennois, E. Orriols. Visual exploration of reaching space during left and right arm movements in 6-month-old infants. Psychologie Française, 2019, 64, pp.55 - 70. 10.1016/j.psfr.2017.06.003 . hal-03486751

\section{HAL Id: hal-03486751 \\ https://hal.science/hal-03486751}

Submitted on 20 Dec 2021

HAL is a multi-disciplinary open access archive for the deposit and dissemination of scientific research documents, whether they are published or not. The documents may come from teaching and research institutions in France or abroad, or from public or private research centers.
L'archive ouverte pluridisciplinaire HAL, est destinée au dépôt et à la diffusion de documents scientifiques de niveau recherche, publiés ou non, émanant des établissements d'enseignement et de recherche français ou étrangers, des laboratoires publics ou privés.

\section{(ㄷ)(1) $\$$}

Distributed under a Creative Commons Attribution - NonCommerciall 4.0 International 


\section{LA COORDINATION VISUO-MANUELLE CHEZ LE BEBE DE 6 MOIS : \\ L'EXPLORATION VISUELLE DIFFERE-T-ELLE EN FONCTION DE LA MAIN}

UTILISEE ?

\section{VISUAL EXPLORATION OF REACHING SPACE DURING LEFT AND RIGHT ARM MOVEMENTS IN 6-MONTH-OLD INFANTS}

Françoise MORANGE-MAJOUX ${ }^{1 *}$, Emmanuel DEVOUCHE ${ }^{1,2}$, Christelle LEMOINELARDENNOIS $^{3} \&$ Eric ORRIOLS ${ }^{4}$

${ }^{1}$ Université Paris Descartes, Institut de Psychologie, Laboratoire de Psychopathologie et Processus de Santé (EA 4057), France

${ }^{2}$ Unité de recherche en Psychiatrie et Psychopathologie, EPS Erasme, France

${ }^{3}$ Université Paris Descartes, Institut de Psychologie, Laboratoire Vision Action Cognition (EA 7326), France

${ }^{4}$ Université Paris Descartes, Institut de Psychologie, Laboratoire Mémoire et Cognition, INSERM S894, France.

* Address for correspondence

F. Morange-Majoux

Université Paris Descartes, Laboratoire de Psychopathologie et Processus de Santé (EA4057)

71 avenue Edouard Vaillant

92774 Boulogne-Billancourt Cedex, France

francoise.morange-majoux@parisdescartes.fr

Françoise Morange-Majoux : développement sensori-moteur chez les enfants tout venants et avec autisme, latéralité manuelle, développement du langage.

Emmanuel Devouche : Interactions sociales précoces, développement social

Christelle Lemoine-Lardennois: Contrôle oculo-moteur, plasticité du système oculo-moteur

Eric Orriols : réalité virtuelle, eye-tracking 


\section{RESUME}

2 La préférence manuelle et la coordination visuo-manuelle émergent progressivement au cours

3 de la première année de vie du bébé avec le développement des gestes de préhension. Le but

4 de cette recherche est de déterminer si l'exploration visuelle au cours des gestes manuels varie

5 en fonction de la main utilisée, et si oui, d'en décrire précisément ses caractéristiques à l'aide

6 d'un système d'eye-tracking. Douze bébés âgés de 6 mois ont été observés dans une situation

7 de préhension (6 essais, 3 avec chaque main). La distribution du regard, la main utilisée, son

8 mouvement, son ouverture et sa position ont été codés à l'aide du logiciel The observer ${ }^{\circledR}$.

9 Les résultats montrent que les bébés explorent leur espace de préhension différemment en

10 fonction de la main utilisée : ils regardent plus l'objet lorsqu'ils utilisent la main droite et plus

11 autour de l'objet lorsqu'ils utilisent leur main gauche témoignant d'une coordination visuo-

12 manuelle asymétrique précoce.

14 Mots-Clefs : Latéralité manuelle, coordination visuo-manuelle, exploration visuelle, enfant, 15 système d'eye-tracking. 


\section{ABSTRACT}

Infant's manual laterality and eye-hand coordination emerge during the second part of the first year of life with the development of reaching. Nevertheless, little is known about the potential asymmetric characteristics of this coordination. The aim of this study was to describe visuospatial exploration in 6-month-old infants during reaching, according to the hand used. More specifically, we examined if the use of the left or the right hand was linked to a specific type of visual exploration. Gaze direction during goal-directed reaching towards an object placed on the table was measured with a remote ASL 504 eye tracker (Bedford MA). Twelve babies aged 6 months were observed during six reaching sessions, alterning three sessions with an object on the left side of the subject and three with an object on the right side. Gaze direction and some hand variables (hand activity, hand opening and hand position from the body) were coded with The Observer software. Results showed that babies visually explore their reaching space differently according to the hand used: they look more at the object when they use their right hand and more around the object when they use their left hand; they also look more often at their left hand than at their right one. These results suggest that an asymmetric visuomanual coordination exists as early as 6 months : vision seems to support (1) left hand during reaching for evaluate distances from object to baby by means of visual feedbacks and (2) right hand for identify what sort of object is. Results are discussed in light of manual specialization and specific hemispheric skills at this age.

Key-words: Manual laterality, visuo-manual coordination, visual exploration, infant, eyetracking 


\section{INTRODUCTION}

Object visuomotor exploration plays a central role in early cognitive development: infants learn about their physical environment, acquire knowledge to plan future actions and develop sensorimotor coordination from these visuomotor experiences. The aim of this paper was to describe how vision participates in reaching, around 6 months, when this hand activity is well-established but not yet automated. More particularly, we analyzed visuo-spatial exploration according to the hand used, in order to evaluate if specific visual strategies could be assigned to manual laterality. In order to specify how visuo-motor coordination is organized, we also observed visuo-spatial exploration according to the movement of the hand, its opening and its position to the object.

The development of eye-hand coordination like in reaching is a good neuroscientist tool, widely used to infer relationships between brain and behavior (Luna, Velanova, \& Geier, 2008). According to the traditional view of infant reaching development, infants use vision, at first, to guide the hand towards the target when they begin to reach, around the age of 4 months (Piaget, 1952; White, Castle, \& Held, 1964), and then they use the visual error between hand and target to correct their ongoing reaches (Bushnell, 1985), when the first successful reaches (grips) appear around 5 months. Between 5 and 7 months, major developments occur in the timing of infant manual anticipation (such as opening of the hand during the movement), indicating that grasp control shifts from being manually guided to being visually guided (Witherington, 2005). However, some results challenge this traditional point of view: one of the most notable is that sight of the hand is not necessary to make successful grasps; Clifton, Muir, Ashmead, and Clarkson (1993) have found that infants from 1.5 to 5 months (6 to 25 -weeks-of-age) touched objects as in the light as in the dark without kinematic differences in reaching (Clifton, Rochat, Robin \& Berthier, 1994). Moreover, infants are capable of completing even relatively complex reaches, such as catching a moving 
object, without visual feedback of the hand (Berthier, Clifton, Gullapalli, McCall, \& Robin, 1996; McCarty et al., 2001). Kinematic changes in reaching in the dark have been reported only in infants aged 15 months (Carrico et al., 2008). However, the fact that infants can reach in the dark does not mean that they don't use vision when it is available (in the light). We can suppose that improvement in reaching is probably the result of general improvements in the use and the integration of different perceptual information in order to make finer a more reliable movements: infants probably use first, proprioceptive information and then visual information, which will become more and more indispensable to modulate reaching during their early development (Thelen et al., 1993; von Hofsten, 1993). We need to have a better understanding of the role played by vision, especially during the onset of prehension, around 6 months, by differentiating the hand used, which regrettably was not mentioned by the previous authors.

In adults, specific visuo-manual asymmetries are reported: when the subject reaches towards an object with his/her left hand, his/her eye movements end up earlier on the object and peak velocity (of eye movements) is reached earlier than when (s)he reaches with his/her right hand (Lavrysen et al., 2008) and saccades reached the target earlier when accompanying leftcompared to right-hand movements (Helsen et al., 1998a, 1998b; Carnahan et al., 1993). Goal-directed one hand movements are predominantly controlled by the contralateral cerebral hemisphere. Traditionally, functional hemispheric specialization is described as right hemisphere advantage for movement planning and/or attentional aspects and left hemisphere advantage for processing information during ongoing movement (Hodges et al., 1997; Carson, 1989). Asymmetries of eye-hand coordination could be explained by the fact that the right hand/left hemisphere system may have higher efficiency in utilizing response-produced feedback (Elliott \& Chua, 1996). This hemispheric specialization also impacts lateral hand use: The right hand is involved in the temporal organization of perceptual and/or motor 
information, during ongoing movements (Flowers, 1975; Bradshaw, Bradshaw, \& Nettleton, 1990; Haaland, Elsinger, Mayer, Durgerian, \& Rao, 2004), and in the planning of sequential acts that require response selection, preparation and/or retrieval (Verstynen, Diedrichsen, Albert, Aparicio, \& Ivry, 2005). The left hand is involved in the spatial planning of a task and in the allocation of attention in space (Carson, 1989; Hodges, Lyons, Cokell, Reed, \& Elliott, 1997; Sainburg, 2002). In this perspective, a manual specialization can be defined independently of handedness: the preferred hand is not always the most relevant according to task specificies : right-handers perform more rapid and accurate reaches with their left hand in a pointing task whereas left-handers are more efficient with their right hand in a fine building task (Gonzalez \& Goodale, 2009 ; Lavrysen et al., 2003).

If the development of handedness is widely studied, infants' early manual specialization is less documented and eye-hand coordination asymmetries have as far as we know never been studied. Some infant studies (von Hofsten, 1979, 1991; Morange-Majoux, Pezé, \& Bloch, 2000; Hopkins \& Ronnqvist, 2002; Ronnqvist \& Domellof, 2006) have shown differences in the kinematics of right- and left-hand movements: right-hand trajectories are smoother, with fewer corrections and fewer movement units -identified kinematically as multiple segments of acceleration and deceleration- than left-hand trajectories. Differences also appear in the quality of movements: pre-reaching movements are more often performed by the left hand, whereas reaching and grip movements are more often performed by the right hand (MorangeMajoux, Pezé, \& bloch, 2000; Morange-Majoux \& Dellatolas, 2010). Finally, infants with a congenital muscular torticollis develops a hand preference on the opposite side to head-tilt. Authors concluded that an increased visual control of the hand during early childhood seems to modulate handedness (Ocklenburg et al., 2010). Such observations are compatible with the position that the right hemisphere controls close-loop movements dependent on sensory 
114 feedback, and the left hemisphere open-loop movements based on well-established motor 115 programs (Haaland \& Harrington, 1989).

116 The Dual Visuomotor Channel theory proposes that visually guided reaching consists of two 117 temporally integrated movements, the Reach and the Grasp, each mediated by separate 118 visuomotor pathways, from occipital to parietofrontal neocortex (Arbib, 1981; Jeannerod, 119 1981, 1999; Rizzolatti et al., 1998; Tanné-Gariépyetal., 2002; Culham \& Valyear, 2006;

120 Cavina-Pratesi et al., 2010; Filimon, 2010; Karl \& Whishaw, 2013). Thus, the initial phase of 121 a reach, mediated by a dorsomedial pathway, serves to transport the hand to the general 122 vicinity of a target and is in relation with the target's extrinsic properties, i.e. localization and 123 orientation (where pathway). The later phase (grasp), mediated by a dorsolateral pathway, is 124 devoted to close the hand, in relation with the target's intrinsic properties, with controlled 125 visual guidance of the hand on the target object, i.e. size and shape (what pathway) (Arbib, 126 Iberall, \& Lyons, 1985; Jeannerod, 1981). We have hypothesized that pre-reaching 127 movements could play a localization role, i.e., provide information concerning the distance of 128 the object from the body, and that the grip movement could be implied in accuracy. The 129 behavioral differences between the two hands, observed in babies, could confirm an 130 asymmetry in information processing between left and right hands: the left hand would be 131 more involved in the "where" pathway and the right one in the "what" pathway.

As stated above, eye-hand coordination shows early hemispheric asymmetries (Lavrysen et al., 2008) even though at these ages, the use of the right-or the left-hand is task-dependent and could be in relation with hemispheric specialization (Arbib, 1981; Morange-Majoux \& Dellatolas, 2010). If seeing his/her hand seems to be not necessary for an infant to grasp an object at 6 months (Clifton et al., 1993, Berthier \& Carrico, 2010) this does not mean that vision does not take a part when it is available. In this perspective, vision could not only participate in reaching but also select differentiate useful information according to the hand 
used. We hypothesized that vision could provide more specifically (1) spatial object information when the infant uses his left hand and (2) intrinsic object information when the infant uses his right hand. If vision participates to the onset of manual specialization, looks will be more centered on the object when the right hand is used and looks will be more widely distributed around the object when the left hand is used. In order to test these hypotheses, we described spatial distribution of looks (on or around the object) during all the reaching (including movement and no movement moments) according to the hand used, hand anticipation and hand localization.

\section{METHOD}

2.1.Participants: Twelve healthy 6-month-old (mean age 6 months, 3 days, ranging from 5 months, 20 days to 6 months, 23 days) full-term infants participated in this study (6 males, 6 females). Ten additional infants were tested, but their data were not included in the final sample, six infants due to technical eye-tracking impairments, two infants because they did not try to reach the object, and two infants due to fussiness. They were all recruited from birth lists in the 13th and 14th districts of Paris. All mothers signed an informed consent form, guaranteeing general anonymous treatment of information. Parents' handedness was controlled (Edinburgh handedness inventory) : 22 were right-handers and 2 were lefthanders

2.2.Eye-tracking system: An eye-tracker was used to study very accurately visual exploration of the baby when he/she had to reach an object. Eye-tracking techniques, in the context of action, allow to measure how infants explore their physical word, and in particular where and what they look at, how they observe the scene spatially (object, around the object) and how many time they look at these parts of the scene, in order to define what strategies they develop when they want to reach an object. Eye-tracking can provide key insights into 
real-time dynamics of perception and action, for infants interact with the environment by the second or the minute. Such rich and detailed information can directly inform about coordination between cognitive, motor and perceptual processes, and more generally enrich theories on the development of asymmetries (Corbetta, Guan, \& Williams, 2012). For this study, we used a remote eye tracker developed by ASL (model R6) that provided eye position coordinates. Head position was recorded with a magnetic tracker, Flock of Birds (Ascension, Burlington, VT) that provides head position coordinates. The ASL system can track eye movements directed at scenes defined in 3-dimensional space and spatially fixed (3D objects located within reaching distance as described in Corbetta et al., 2012). Furthermore, the system was configured to record gaze position on a horizontal plan (scene plan), i.e. the table in the present study. Using both head position data and gaze vector position data, the system determines where on the surface the subject is looking (Eye-Trac 6 Control Unit and User Interface Software Reference Manual, pp 68). The only constraint was baby's head had to remain stable.

2.3.Apparatus: The experimental apparatus was composed of an eye-tracking system, a scene camera above the baby, a minibird eye-tracker, a front webcam, two computers and three control screens. All components of the experimental apparatus were synchronized and linked (Figure 1).

Eye-tracking system included a remote optics eye camera that allowed the infant approximately one square foot of head movement and eliminated the need for head restraint. This eye-tracker was placed in front of the infant, on the table, at a distance of 50 $\mathrm{cm}$. The infant's line of gaze was measured by computing the pupil-corneal reflection at a sampling rate of $50 \mathrm{~Hz}$ (Figure 1C). The accuracy level was about $0.5^{\circ}$ of visual angle, 
and the resolution was about $0.25^{\circ}$ of visual angle. Performance of both eyes was measured.

A scene camera (ceiling camera), placed above the table, captured the table during the experiment and gave us a still shot of the scene. Live recording of the table was synchronized on line with the remote optics eye camera by computer which calculated the superimposition of specific gaze position (symbolized by two crossing lines) and a still shot of the table (Figure 1A). ASL system was conceived to create a plane projection of gaze direction vectors and to compute the correlation between calibration points and gaze direction vectors simultaneously measured. Spatial coordinates were then translated into eye-tracking coordinates during the calibration phase and calibration points were linked to the still shot of the scene (see Calibration phase section below).

The scene camera also captured the infant's hands activity. The recording was used for coding hands activity (Figure 1A and 2) with The Observer (C) software (see Coding section). Moreover, the superimposition of the still shot with the gazes gave an indication of when infants looked at their hands.

- $\quad$ Insert figure 2 about here -

Head position was recorded with a magnetic tracker, Flock of Birds (Ascension, Burlington, VT). This device has a Mini Bird head tracker that provides head position coordinates, so that the ASL pan/tilt camera can reconnect to the eye, in case of rapid head movements (see Gredebäck et al., 2002 and Aslin \& Murray, 2004). (see figure .1B)

Lastly, a front webcam was added and synchronized to the two other cameras to record infants' behavior, facial expressions and head orientation (Figure 1B). This additional camera provided information about the baby's behaviors and allowed to appreciate the consistency with information of remote eye-tracking detection. 
The three videos were all captured with the same computer to obtain a synchronized video

213 recording throughout the experiment (Figure 1).

214

2.4.Material: the object to reach was a $2.5 \times 2 \mathrm{~cm}^{2}$ little yellow Kinder@ chick graspable by 6months-old infants. This toy was placed in front of the infant, on the table, at a distance of $25 \mathrm{~cm}$, just at a reachable distance, inside the tracking window of the ASL system. The ASL system detects accurately gaze positions on the plan (2D) but the use of a 3D object generates a decrease in accuracy, due to the object's height (3D). Indeed, the space behind the object could not be seen from the infant's perspective, and was called the occlusion area (see figure 1). Thus any gazes at that space detected by the ASL system was in fact a gaze at the object. This occlusion area was deducible $(1.5 \mathrm{~cm}$ behind $)$ on the basis of object's height and the level of the infant's eyes. In order to determine the impact of this occlusion area on our data, an analysis of the distribution of gazes around the object revealed that a majority was in front of the object $(88 \%)$ or on its left- or right-side $(11 \%)$. Gazes behind the object were thus very rare $(<1 \%)$ and kept out of the study.

2.5.Procedure: The experiment took place in a quiet room of the Psychology Department at Paris Descartes University. Infants were seated on their parent's lap, facing a table with their hands free to move and the body maintained against the adult to limit head movements of the baby.

The parents remained quiet during the entire experiment (approximatively $15 \mathrm{~min}$ ). Experiment procedure always contained a calibration and a test phases.

- Calibration phase: Nine calibration target points were used to calibrate the scene plan (see Figure 3). These nine points were identifiable by landmarks drawn on the table. A transparent flashing ball ( $2 \mathrm{~cm}$ diameter) was used during calibration phase. This ball was successively positioned on the nine markers on the table in order to create a bijection of any point of the scene plan onto the window defined by these nine gaze direction vectors. 
For each calibration point, the experimenter A (standing behind the remote optic eye camera) placed the ball on the marker; when a gaze on the ball was detected by the eyetracker, experimenter B approved manually on the computer the calibration point measured. This procedure was repeated for each calibration points. At the end, each of the calibration point coordinates were translated into visual vectors coordinates and linked to a scene plan image (scene camera recorded continuously the same scene). In practice, a cross appeared on the scene plan video recording each time an infant looked on the table

- Test phase: The little yellow chick was placed on the table, on the right or on the left side of the baby, inside the scene plan, out of sight of the baby by using a cardboard. An experimenter stood behind the remote optic eye camera in order to present the test object to the infants. Six trials were performed, alternatively on the left and the right sides of the infant in order to induce ipsilateral movements (Fagard, Spelke, \& Von Hofsten, 2009; Morange \& Bloch, 1996; Morange-Majoux et al., 2012). First side of presentation was counterbalanced across infants. At the beginning of each trial an experimenter positioned a large piece of cardboard $(40 \times 60 \mathrm{~cm})$ in front of the baby and a second experimenter placed the object behind the cardboard, on the table, in the left or right position (the cardboard was large enough to hide both possible positions of the object). At this stage, the object and its position were hidden by the cardboard. Then the first experimenter removed the cardboard, thus uncovering the object. The trial began with the first look at the object (as identified by the eye tracker), and ended at the first contact between the hand tested and the object (not after reaching or grip because it would have been 
impossible to determine if the subject looked at the object or his hand). Both eye and hand

263 activities were recorded during the trial.

264 2.6.Coding: Both hand and eye activity data collected by ASL system were coded with the 265 Observer XT10@ software on the video given in Figure 1A, which combined scene video 266 recording and eye tracking point's projection. We chose to recode eye activity initially 267 coded by ASL system with the Observer XT10@ software in order to (i) check data and (ii) 268 avoid erroneous data. (i) for example, when the subject looked at the experimenter, ASL 269 system lost looks. Nevertheless, with the video given in figure 1A, we reconsidered these lost data and coded them as looks at the experimenter with Observer XT10@ software. (ii) for example, when ASL system identified looks at baby's hand, we systematically checked 272 with the video given in figure 1A if the hand was posed on the table or aloft. Because of 273 the position of the scene camera above the hands of the baby, when the hand was aloft, 274 ASL system identified a look on the hand whereas the look was under the hand on the 275 table. In this case (very few situations), the look at the hand was reconsidered and coded as 276 a look at the table with Observer XT10@ software. Time-position data were sampled at 25 $277 \mathrm{~Hz}$ (25 images per second). Looks and both hands were coded independently, by two 278 independent observers, blind to the condition and hypotheses. The inter-rater reliability of 279 the two coders, based on all trials, was $99 \%$ for eye coding and $96 \%$ for movement coding. 280 Contentious trials were re-examined by both experimenters and re-coded together until a $281 \quad 100 \%$ inter-rater agreement was eventually reached.

$282>$ Look durations were coded during all the trial according to five areas: (1) on the object (with a radius of $0.5 \mathrm{~cm}$ around the object), (2) around the object (radius ranging from $0.5 \mathrm{~cm}$ to $5 \mathrm{~cm}$ ), (3) on the table (i.e. elsewhere outside the $5 \mathrm{~cm}$ radius), (4) on the right hand and (5) on the left hand. A look was detected when a 
cross (intersection between a horizontal line and a vertical line) appeared on the video: this intersection being a staring (looking) point (see Figure 1A).

Right- and left-hand durations were coded during all the trial according to three hand characteristics: (1) hand activity (during the trial baby could move or not his/her arm towards the object); (2) hand opening (widely opened or not) and (3) localization of the hand with respect to the baby's body (the hand of the baby could be near him or near the object; we defined two modalities allocentered and egocentered: the boundary between the two modalities was defined by the median distance between the body and the object). The word "hand" used in the results section always refers to the ipsilateral hand according to the object's position. Analyzes performed on the contralateral hand were systematically specified.

All these codings allowed to analyze visuo-spatial distribution according to specific hand parameters in order to qualify and potentially precise eye-hand coordination.

2.7.Statistics: Given that trials $(72 ; 36$ performed with the left hand, 36 performed with the right hand) did not have the same durations, they were analyzed according to the total duration of the trial in terms of percentages (proportions of time), by mean of a two way repeated measures ANOVA with hands (right / left) and object position (right / left) as within subject factors, and with partial eta squared values $\left(\eta^{2}\right)$ as an index of effect size. For each measure we computed a Shapiro-Wilk test to determine whether the hypothesis of normality could be rejected. Chi square test was used to analyze cross-tabulated data, with Cramer's V as an index of effect size. All analyses were done with Stata 14.

\section{RESULTS}

\subsection{Hand characteristics}


310 All right side objects were reached by the right hand (and reciprocally the left side objects

311 were reached by the left hand.

312 3.1.1. Hand activity: On average, infants did not move their hands during $37 \%$ of the trial's 313 time (ranged from 3,8\% to 96,2\%). Shapiro-Wilk tests computed for each of the four 314 measures were all non-significant (all p-values above .08). The two-way repeated measures

315 ANOVA conducted on the proportion of time during which the hand remained stationary 316 revealed no significant effect of object position $\left(F(1,11)<1 ; p=.94 ; \eta_{p}{ }_{p}<.001\right)$, but a significant 317 effect of the hand: the left hand remained more often stationary than the right one (47\% vs $31830 \% ; F(1,11)=6.60 ; p=.028 ; \eta^{2}=.40$; Figure 4) during a trial. A specific analysis carried out 319 on the contralateral hand revealed that, an object placed on the right side significantly 320 increased right hand activity and strongly reduced left hand activity (difference of 25 points 321 between both hands, $50 \%$ vs $25 \%$ ), whereas a presentation on left side activated both hands in 322 the same way $\left(F(1,11)=5.16 ; p=.047 ; \eta_{p}^{2}=.34\right)$. Furthermore, only $9 \%$ of trials with left 323 reachings were performed without stationary hand moments, whereas $33 \%$ of trials with right 324 movements did not include any stationary hand moments. In other words, babies kept his/her 325 hand stationary more often during their left- than their right -hand reachings.

327 Last, we examined how many trials started with no movement of the hand -left or right- (all 328 trials began with a look on the table). Analysis showed that $74 \%$ of left movements were 329 initiated first by a look during which the hand did not move, against $47 \%$ for the right hand 330 (difference of $26.3 \%$; IC95\% $=(3.4 ; 45.6)$ ). Babies tended to move their right hand 331 immediately towards the object, as soon as they looked at it, in half of the right hand 332 movements. 
3.1.2. Hand opening: On average, infants' hands were widely opened $89 \%$ of the time. Shapiro-Wilk test was significant for one measure (right hand / object right; $p=.0241$ ). The two-way repeated measures ANOVA, conducted on the proportion of time where the hand was wide open, revealed no significant effect, neither of the hand $(F(1,11)=1.33 ; p=.27$; $\left.\eta_{p}^{2}=.11\right)$, nor of the object's position $\left(F(1,11)=1.11 ; p=.32 ; \eta_{p}^{2}=.09\right)$, suggesting that movements have the same profile, whichever hand is used.

3.1.3. Hand position from the body: On average, $47 \%$ of infants' manual activity was distributed near the object (allocentered). Shapiro-Wilk tests computed for each of the four measures were all not significant (all p-values above .20). The two-way repeated measures ANOVA conducted on the proportion of time the hand was allocentered revealed no significant effect, neither for the hand $\left(F(1,11)<1 ; p=.54 ; \eta^{2}=.04\right)$, nor for the object position $\left(F(1,11)<1 ; p=.66 ; \eta^{2}=.02\right)$.

\subsection{Visuo-spatial exploration during a trial}

Automatic detection of staring points by ASL system was performed, on average, $47 \%$ of the total duration of trials (ranging from $29 \%$ to $86 \%$ depending on the infant). No difference was found across trials. As described in Method section, we have recoded all eye-tracking data with Observer XT10@ in order to check ASL detection. Five areas into the scene plan where babies could look at were defined: on the object, around the object, on the table, on their left hand and on their right hand. In order to examine specifically missing data, we have completed our analysis by adding babies' looks at the experimenter from the front webcam video (Figure 1B) with Observer XT10@ software. Results showed that babies looked at the experimenter on average $15 \%$ of the total duration of trials, reducing missing data to $38 \%$. 
Figure 5 illustrates the distribution of gazes at the different areas of the scene plan according to the hand used. When infants used their left hand, they tended to look more around the object and at their left hand, whereas when they used their right hand, their looks were more equally distributed toward the object and around it. Otherwise, infants tended to look at their ipsilateral hand in presence of a lateral reachable object. The two distributions were found to be significantly different (Chi square $=17.64, p=.014$, Cramer's V $=0.30$ ).

- Insert Figure 5 about here -

In order to appreciate more accurately vision control on the different phases of the reaching, we have examined hand activity during the trial:

3.2.1. When the hand was remained stationary: Figure 6 presents the distribution of gazes on the different areas of the scene plan when the hand ipsilateral to the object did not move. The most remarkable result is that infants looked at mainly around the object when the object was placed on the left side, and never at their right hand. On the contrary, their looks were more localized on the object when the object was in the right side. The two distributions were found to be significantly different (Chi square $=22.59, p<.02$, Cramer's $V=0.34$ ).

\section{- Insert Figure 6 about here -}

3.2.2. During hand movement: Figure 7 presents the distribution of gazes during right- and left movement. Results showed that whatever the hand used, babies' looks were equally distributed between object and around it. The most notable result is that babies looked at more their left hand when they performed a reaching with the left hand than their right one when they performed a reaching with this one. Both distributions were significantly different (Chi square $=32.64, \mathrm{p}<.01$, Cramer's $V=0.40)$. 
The last analysis was dedicated to examine more accurately gazes on the hands and to answer to this question: when an infant looks at his hands, what do the hands do ? We compared proportion of time during which the infant looked each hand considering position, activity and anticipation of hands. For this analysis, two infants were excluded, because they never looked at their hands. Shapiro-Wilk tests ran on the 6 distributions revealed that the hypothesis of normality could be rejected for two measures (left hand allocentered and left hand open; respectively $p=.022$ and $p=.029)$. When an infant looked at his hand, it was moving half of the time, with no significant differences between hands (respectively 54\% for the left hand and $45 \%$ for the right hand; $t(9)<1 ; p=.68)$ and allocentered, on average, $70 \%$ of the time, with no significant differences between left and right hands (respectively $71 \%$ and $68 \% ; t(9)<1$; $p=.62)$. Finally, the hand was open $82 \%$ of the time, with a left hand more often open $(96 \%)$ than the right hand (68\%), a 28 points difference however not significant $(t(9)=1.74, p=.12)$.

\section{DISCUSSION}

The present study aimed to describe how babies visually explore their reaching space in the presence of a target-object and to determine if this visual exploration varies according to the hand used and some hand characteristics (manual anticipation, hand activity, hand / object position). This original eye-tracking design allowed us to investigate new levels of analyses, by examining precisely the distribution of infant gazes when an object was presented to be caught. In this context, this study provides the first description, with a remote eye-tracker, of visuospatial exploration of the infant's reaching space during a movement, according to the hand used. Several results can be discussed and some conclusions may be drawn.

First, result stationary hand s showed a greater activity of the right hand, whatever the location -right or left- of the object. This was confirmed by the high proportion (1/3) of trials 
with right hand reaching, always in movement stationary hand. In a previous study, we had shown that the right hand was always more in motion than the left one (Morange-Majoux et al., 2000). Thus, a context of reaching stimulates right hand movements. This is attested by others studies (Rönnqvist \& Domellöf, 2006; Michel et al., 2006), showing an increase in right hand use from the age of 6 months, interpreted as the onset of right handedness. In our study, the greater activity of the right hand probably confirms the beginning of this manual asymmetry.

Second, results about visuospatial exploration provide a great contribution to our understanding of visuo-manual coordination. Visual exploration of the reaching space is mainly dominated by two sources of exploration: the space all around the object and the object itself. The significant result is that an infant does not explore in the same way his reaching space, according to the hand used and to its activity. During moments where the hand remained stationary, infants visually explore the space around the object placed on the left side and look at specifically the object placed on the right side. When they perform a reaching, their looks are more equally distributed toward the object and around it. We can assume that looking at the object allows the infant to learn more about the object's physical characteristics before contacting an object with the right hand. This is compatible with the better ability of the right hand to catch and manipulate objects observed in previous studies (Michel \& Harkins, 1986; Corbetta et al., 2006; Michel et al., 2006). We can also hypothesize that looking around the object brings information about its location and its distance from the body, before reaching it with the left hand. These differences between the two hands, on the visuospatial exploration of reaching space, reveal not only asymmetric visuo-manual coordination as early as 6 months, but also specific strategies according to the steps of reaching. The well-known studies about hemispheric specialization can enlighten these results: indeed, the right hemisphere holds an advantage in movement planning and/or 
attentional aspects (Hodges et al., 1997; Carson, 1989), whereas the left hemisphere is faster

429 at processing information during the ongoing movement; this information could be either visual or non-visual (Buekers \& Helsen, 2000; Elliott et al., 1999; Roy et al., 1994; Lavrysen et al., 2003). In this context, when the baby has to perform a left hand movement (right hemisphere), his/her gazes are distributed all around the object, especially before the movement, during moments where the hand remained stationary, to evaluate the object's location. When the baby performs a right hand movement, most gazes are focused on the object, from the beginning to the end of the trial.

In previous studies (Morange et al., 1996; Morange-Majoux et al., 2000; 2010; MorangeMajoux, 2011), we have shown a lateralization of reaching development : babies use more often their left hand to perform approach movements, whereas they use more often their right hand to perform grip movements. These results have been interpreted as evidence for manual specialization as early as 4-month-olds, The present study brings evidence that vision participates to manual specialization, in a harmonious, coordinated way: vision is used to explore all the reaching space when the left hand contributes to evaluate distance and location; while vision is used to examine an object, when the right hand is used to determine the object's intrinsic properties. In other words, there is an early asymmetric visuomotor 445 coordination, probably supported and mediated by different sensorimotor channels (Karl \& 446 Whishaw, 2013; 2014).

447 These results can be compared to researches in adults, which have demonstrated a 448 specialization in the use of both hands (Carson, 1989; Bradshaw \& Nettleton, 1990; Hodges et 449 al., 1997; Sainburg, 2002; Bradshaw et al., 1990; Haaland et al., 2004) and in visuo-manual 450 coordination (Lavrysen et al., 2008). They are in agreement with the dual visuomotor channel theory, which proposes that visually guided reaching consists of two movements, a first one, which transports and guides the hand in relation to the extrinsic features (location) of the 
target, while another one opens, shapes and closes the hand on the target, in relation with its intrinsic features (size, shape). In this perspective, our study shows that each movement is allocated to a specific hand. One prediction of the dual visuomotor channel theory of reaching, is that development should feature independence in the maturation of the two movements. Researches have shown that movements to locate object occur before movements to grip objects (Von Hofsten, 1984; Savelsbergh \& van der Kamp, 1994; Morange \& Bloch, 1996; Morange-Majoux et al., 2000; 2010). During development, reaching and grasping become integrated in a seamless visually guided act. We argue that these behavioral differences between the two hands, observed in babies, could confirm an asymmetry in information processing between the left and the right hands: the left hand would be more involved in the "where" pathway and the right one in the "what" pathway.

Third, another notable result concerns gazes on the left hand (31\%), especially during moving moments. It will be interesting in a future study to determine at what time during the trial these looks on the left hand in progress appear. Numerous researchers have investigated the role of vision in prehension (Bushnell, 1985; Carrico et al., 2008; Berthier et al., 2010; Hofsten, 1991): some of them propose that infants use sight of the hand to guide early reaching (Piaget, 1952; Bushnell, 1985), others consider that sight of the hand is not necessary to make successful grasps (Clifton et al., 1994; Carrico et al., 2007). As we have suggested, babies use visual information when it is available even if babies can reach objects without the sight of their hand. Our results show that when babies can see their hands, they significantly look at their left hand more than their right hand during reaching. This increase of gazes at the left hand could be interpreted as a great left hand expertise for visuospatial processes: infants look at the most visuo-spatially adapted hand in order to evaluate distances (i.e. from their hand to the object) and localize an object. Furthermore, analyzes regarding the number of wig-wag between an object and the left hand is twice higher than with the right hand 
confirming its role to evaluate distances. These results allow us to draw a complex asymmetric visuo-manual coordination, which appears as early as 6 months: when babies use their left hand they tend to look at around the object before to initiate their reaching in order to evaluate and determine the distance, then they perform their movement while looking their left hand and doing wig-wag between object and the left hand. When babies use their right hand, they tend to look at around and on the object, before and during the movement. Vision supports left hand during reaching for evaluate distances by means of visual feedbacks. This visuo-manual coordination appears still integrated and favors knowledge about physical environment. This visuo-manual coordination probably finds its origin in hemispheric specialization, as Lavrysen and collaborators (2008) have suggested. The left hand system may be more effective at using visual feedback and retro-control via right hemisphere and the right hand system may be more effective at using feedforward and predictive control via left hemisphere (Roy and Kalbfleisch, 1994). Previously, we have showed that left-hand made numerous changes in direction suggesting a spatial scanning, such adjustments requiring more time (Morange-Majoux et al., 2000). Results achieved in the dark or without visual feedback of the hand (Berthier et al., 1996; McCarty et al., 2001) are not contradictory with our results: at this age, vision is not used to guide movement but probably more to inform the baby on object extrinsic properties (where it is ?) and intrinsic properties (what is it ?). It would be interesting to examine manual laterality in the dark and in particular, to determine if the use of the left hand is disturbed or not (without possibility of visual feedbacks) and to compare kinematics of left- and right reaching in light and dark in order to examine not only the onset of visuo-manual coordination but also its asymmetry. Moreover, it will be interesting to describe longitudinally the development of the role of vision according to the hand used.

In addition, results showed that when an object is presented in front of a baby, his/her hands are, most of the time, widely open, indicating that the baby is ready to reach out to the object, 
503 which confirms what had been observed in others studies ((Fagard, 2000; Fagard \& Pezé, 504 1997; Hofsten \& Fazel-Zandy, 1984). Sacrey and Whishaw (2010) have shown that collection 505 (hand shape in which digits are lightly flexed and closed) becomes increasingly prominent 506 from 1 to 6 months. It replaces a clenched fist that was typically held proximal to the upper 507 torso. This collation development is probably the precursor of other hand shaping movements, 508 like skilled movements of grasping and reaching.

509 In conclusion, we argue that eye-tracking may be used in the context of action. It raises novel 510 questions about the development of visuo-manual coordination. It allows to explore with good 511 accuracy where infant direct their gaze on a scene (Corbetta et al., 2012), what they look at 512 and how many times they do so. We are aware that the loss of eye-tracking data (38\%) during 513 head turns or others behaviors preventing eye capture is a serious limitation of our study. 514 Head-mounted eye-trackers do show advantages to study infant perception in more natural 515 and less-constrained environments (Corbetta et al., 2012). 


\section{References}

Arbib, M.A. (1981). Perceptual structures and distributed motor control, in Brooks, B. (Ed) Handbook of Physiology, Section1, Vol.2, Part2, (pp. 1449-1480). Bethesda, MD: American Physiological Society.

Arbib, M., Iberall, A., \&Lyons, T.D. (1985). Coordinated control program for movements of the hand, in hand function and the neocortex, Experimental Brain Research Supplementum, 10, 111-129.

Aslin, R.N., \& McMurray, B. (2004). Automated corneal-reflection eye tracking in infancy: Methodological developments and applications to cognition, Infancy, 6, 155-163.

Berthier, N.E., Clifton, R.K., Gullapalli, V., McCall, D.D., \& Robin, D.J. (1996). Visual information and object size in the control of reaching, Journal of Motor Behavior, 28, $187-197$.

Berthier, N.E., \& Carrico, R.L. (2010). Visual information and object size in infant reaching, Infant Behavior \& Development, 565-566.

Bradshaw, J.L., Bradshaw, J. A., \& Nettleton, N.C. (1990). Abduction, adduction and hand differences in simple and serial movements, Neuropsychologia, 28, 917-931.

Bushnell, E.W. (1985). The decline of visually guided reaching during infancy. Infant Behavior and Development, 8(2), 139-155.

Buekers, M.J., \& Helsen, W.F. (2000). Vision and laterality: does occlusion disclose a feedback processing advantage for the right hand system? Cortex, 36(4), 507-519.

Carnahan, H., Roy, E., \& Elliott, D. (1993). Eye, head and hand coordination while pointing with the left and right hands, Journal of Human Movement Studies, 25, 1-10.

Carrico, R.L., \& Berthier, N.E. (2008), Vision and precision reaching in 15-month-old infants, Infant Behavior \& Development, 31, 62-70. 
Carson, R.G. (1989). Manual asymmetries: feedback processing, output variability and spatial complexity: resolving some inconsistencies, Journal of Motor Behavior, 21, 38-47.

Carson, R.G., Goodman, D., Chua, R., \& Elliott, D. (1993). Asymmetries in the regulation of visually guided aiming, Journal of Motor Behavior, 25, 21-32.

Cavina-Pratesi, C., Ietswaart, M., Humphreys, G.W., Lestou, V., \& Milner, A.D. (2010). Impaired grasping in a patient with optic ataxia: primary visuomotor deficit or secondary consequence of misreaching? Neuropsychologia 48, 226-234.

Clifton, R.K., Muir, D.W., Ashmead, D.H., \& Clarkson, M.G. (1993). Is visually guided reaching in early infancy a myth? Child Development, 64, 1099-1110.

Clifton, R.K., Rochat, P., Robin, D.J., \& Berthier, N.E. (1994). Multimodal perception in the control of infant reaching, Journal of Experimental Psychology, Human Perception and Performance, 20, 876-886.

Colombo, J., (1993). Infant cognition: Predicting later intellectual functioning. Newbury Park, CA Sage.

Corbetta, D., Guan, Y., \& Williams, J.L. (2012). Infant Eye-Tracking in the Context of GoalDirected Actions, Infancy, 17(1), 102-125.

Culham, J.C., \& Valyear, K.F. (2006). Human parietal cortex in action, Current Opinion in Neurobiology, 16, 205-212.

Elliott, D., \& Chua, R. (1996). Manual asymmetries in goal-directed movement, Manual Asymmetries in Motor Performance. CRC Press, Florida, (pp.143-157).

Elliot, D., Elliott D., Heath M., Binsted G., Ricker K.L., Roy E.A., \& Chua R. (1999). Goaldirected aiming: correcting a force-specification error with the right and left hands, Journal of Motor Behavior, 31:309-324. 
Fagard, J. (2000). Linked proximal and distal changes in the reaching behaviour of 5- to 12month-old human infants, grasping objects of different sizes, Infant Behavior and Development, 23, 317-329.

Fagard, J., \& Pezé, A. (1997). Age changes in interlimb coupling and the development of bimanual coordination, Journal of Motor Behavior, 29, 199-208.

Fagard, J., Spelke, E. \& von Hofsten, C. (2009). Reaching and grasping a moving object in 6-, 8-, and 10-month-old infants: Laterality and performance, Infant and Behavior Development, 32; 132-147.

Falck-Ytter, T., Gredeback, G. \& von Hofsten, C. (2006). Infants predict other people's action goals, Nature Neuroscience, 9, 878-879.

Filimon, F. (2010). Human cortical control of hand movements: parieto frontal net- works for reaching, grasping, and pointing, Neuroscientist, 16, 388-407.

Flowers, K. (1975). Handedness and controlled movement, British Journal of Psychology, 66, $39-52$.

Gonzalez, C.L., \& Goodale, M.A. (2009). Hand preference for precision grasping predicts language lateralization, Neuropsychologia, 47 (14), 3182-3189.

Gredebäck, C., von Hofsten, C., \& Boudreau, J.P. (2002). Infants' visual tracking of continuous circular motion under conditions of occlusion and non-occlusion, Infant Behavior and Development, 25, 161-182

Haaland, K.Y., \& Harrington, D.L. (1989). Hemispheric control of the initial and corrective components of aiming movements, Neuropsychologia, 27, 961-969.

Haaland, K.Y., Elsinger, C.L., Mayer, A.R., Durgerian, S., \& Rao, S.M. (2004). Motor Sequence complexity and performing hand produce differential patterns of hemispheric lateralization, Journal of Cognitive Neuroscience, 16, 621-636. 
Helsen, W.F., Elliott, D., Starkes, J., \& Ricker, K.L. (1998a). Temporal and spatial coupling of point of gaze and hand movements in aiming, Journal of Motor Behavior, 30, 249259.

Helsen, W.F., Starkes, J.L., Elliott, D., \& Buekers, M.J. (1998b). Manual asymmetries and saccadic eye movements in right-handers during single and reciprocal aiming movements, Cortex, 34, 513-529.

Hodges, N. J., Lyons, J., Cockell, D., Reed, A., \& Elliott, D. (1997). Hand, space and attentional asymmetries in goal-directed manual aiming, Cortex, 33, 251-269.

Hofsten, C. (1979). Development of visually directed reaching: the approach phase, Journal of Human Movement Studies, 5, 160-178.

Hofsten, C., \& Fazel-Zandy, S. (1984). Development of visually guided hand orientation in reaching. Journal of Experimental Child Psychology, 38, 208-219.

Hofsten, C. (1991). Structuring of early reaching movements: a longitudinal study, Journal of Motor Behavior, 23, 280-292.

Hofsten, C. (1993). Prospective control: a basic aspect of action development, Human development, 36(5), 253-270.

Hofsten, C. (2005). On the development of perception and action. In K. Connolly \& J. Valsiner (Eds.), Handbook of developmental psychology. London: Sage.

Hopkins, B., \& Ronnqvist, L. (2002). Facilitating postural control: effects on the reaching behavior of 6-month-old infants, Developmental Psychobiology, 40 (2), 168-182.

Jeannerod, M. (1981). Inter segmental coordination during Reaching at natural visual objects. In Long, J. and Baddeley, A. (Eds), Attention and performance IX, (pp. 153-169). Hillsdale, NJ: Lawrence Erlbaum Associates. 
Jeannerod, M. (1999). Visuomotor channels: their integration in goal-directed prehension, Human.Movement.Science, 18,201-218.

Karl, J.M., \& Whishaw, I.Q. (2013).Different evolution are origins for the reach and the grasp: an explanation for dual visuomotor channels in primate parieto frontal cortex, Frontiers of Neurology, 4, 208.

Karl, J.M., \& Whishaw, I.Q. (2014). Haptic grasping configurations in early infancy reveal different developmental profiles for visual guidance of the Reach versus the Grasp, Experimental brain research, 232(10), 3301-3316.

Lavrysen, A., Helsen, W.F., Tremblay, L., Elliott, D., Adam, J.J., Feys, P., \& Buekers, M.J. (2003). The control of sequential aiming movements: the influence of practice and manual asymmetries on the one-target advantage, Cortex 39, 307-325.

Lavrysen, A., Elliott, D., Buekers, M.J., Feys, P., \& Helsen, W.F. (2007). Eye-hand coordination asymmetries inmanual aiming, Journal of Motor Behavior, 39, 9-18.

Lavrysen, A., Heremans, H., Peeters, R., Wenderoth, N. Helsen, W., Feys, P. \& Swinnena, S. (2008). Hemispheric asymetries in eye-hand coordination, NeuroImage, 39, 1938-1949.

Luna, B., Velanova, K., \& Geier, F. (2008). Development of eye-movement control, Brain and Cognition, 68, 293-308.

McCarty, M.E., Clifton, R.K., Ashmead, D.H., Lee, P., \& Goubet, N. (2001). How infants use vision for grasping objects, Child Development, 72, 973-987.

Michel, G. (1992). Maternal influences on infants hand-use during play with toys, Behav. Genet. 22, 163-176.

Michel, G. Michel, G.F., Sheu, C.F., Tyler, A.N., \& Ferre, C.L. (2006). The Manifestation of infant hand-use preferences when reaching for objects during the seven- to thirteenmonth age period, Developmental Psychobiology, 48, 436-443. 
634 Mieschke, P.E., Elliott, D., Helsen, W.F., Carson, R.G., \& Coull, J.A. (2001). Manual 635 asymmetries in the preparation and control of goal-directed movements, Brain and 636 cognition,. 45, 129-140.

637

638

639

640

641

642

643

644

645

646

647

648

649

650

651

652

653

654

655

656

Morange-Majoux, F. (2011). Manual exploration of consistency (soft vs hard) and handedness in infants from 4 to 6 months old, Laterality, 16(3), 292-312.

Morange, F., \& Bloch, H. (1996). Lateralization of the approach movement and the prehension movement in infants from 4 to 7 months, Early Development and Parenting, $5,81-92$.

Morange-Majoux, F., Peze, A., \& Bloch, H. (2000). Organisation of left and right hand movement in a prehension task: a longitudinal study from 20 to 32 weeks. Laterality: 5 (4), 351-362.

Morange-Majoux, F., \& Dellatolas, G. (2010). Right-left approach and reaching arm movements of 4-month infants in free and constrained conditions, Brain and Cognition, $72,419-422$.

Morange-Majoux, F., Lemoine, C. \& Dellatolas, G. (2012). Early manifestations of manual specialization in infants: A longitudinal study from 20 to 30 weeks using reaction time, Laterality, 18, 231-250.

Piaget, J. (1952). The origins of intelligence in the child. New York: Routledge.

Rizzolatti, G., Luppino, G., \& Matelli, M. (1998). The organization of the cortical motor system: new concepts. Electroencephalogr. Clin Neurophysiol. 106, 283-296.

Rönnqvist, L., \& Domellöf, E. (2006). Quantitative assessment of right and left reaching movements in infants: A longitudinal study from 6 to 36 months, Developmental Psychobiology, 48(6), 444-459. 
Rose, S.A., Feldman, J.F., \& Jankowski, J.J. (2001a). Attention and recognition memory in the first year of life: A longitudinal study of preterms and full-terms, Developmental Psychology, 37, 135-151.

Rose, S.A., Feldman, J.F., \& Jankowski, J.J. (2001b). Visual short-term memory in the first year of life: Capacity and recency effects, Developmental Psychology, 37, 539-549.

Roy, E.A., \& Elliott, D., (1989). Manual asymmetries in aimed movements, Quarterly Journal of Experimental Psychology, 41A, 501-516.

Roy, E.A., Kalbfleisch, L., \& Elliott, D., (1994). Kinematic analyses of manual asymmetries in visual aiming movements, Brain and Cognition: 24.,(2), 289-295.

Sacrey, L.A.R., \& Whishaw, I.Q. (2010). Development of collection precedes targeted reaching: resting shapes of the hands and digits in 1-6-month-old human infants, Behavioural brain research, 214(1), 125-129.

Savelsbergh, G.J., \& van der Kamp, J. (1994). The effect of body orientation to gravity on early infant reaching. Journal of Experimental Child Psychology, 58(3), 510528.Sainburg, R. L., (2002). Evidence for a dynamic-dominance hypothesis of handedness, Experimental Brain Research: 142., (2), 241-258.

Schulter, N.D., Rushworth, M. F., Passingham, R.E., \& Mills, K.R. (1998). Temporary interference in human lateral premotor cortex suggest dominance for the selection of movements. A study using transcranial magnetic stimulation, Brain, 121, 785-799.

Smith, L.B., \& Thelen, E. (1993). A dynamic systems approach to development. Cambridge, MA : MIT Press.

Starkes, J., Helsen, W., \& Elliott, D. (2002). A menage a trois: the eye, the hand and on-line processing, J. Sports Sci. 20, 217-224. 
680 Tanné-Gariépy, J., Rouiller, E.M., \& Boussaoud, D. (2002). Parietal inputs to dorsal versus 681 ventral premotor are as in the macaque monkey: evidence for largely segregated visuomotor pathways, Experimental.Brain Research, 145, 91-103.

683

684

685

686

687

688

689

690

691

692

693

694

695
Thelen, E., Corbetta, D., Kamm, K., Spencer, J.P., Schneider,K., \& Zernicke, R. (1993). The transition to reaching: Mapping in tention to intrinsic dynamics, Child Development, 64, $1058-1098$.

Todor, J. I., \& Cisneros, J. (1985). Accommodation to increased accuracy demands by the right and left hands, Journal of motor behavior, 17(3), 355-372.

Verstynen, T.D., Diedrichsen, J., Albert, N., Aparicio, P., \& Ivry, R.B. (2005). Ipsilateral motor cortex activity during unimanual hand movements relates to task complexity, Journal of Neurophysiology, 93, 1209-1222.

White, B.L., Castle, P., \& Held, R. (1964). Observations on the development of visually directed reaching, Child Development, 35, 349-364.

Witherington, D. C. (2005). The development of prospective grasping control between 5 and 7 months: A longitudinal study, Infancy, 7, 143-161 
Figure 1: Experimental design. Eye-tracking system was configured to record looks on a horizontal plan. 1A: Scene plane recorded by the scene camera. Live recording of the table was synchronized on line with the remote optics eye camera by computer which calculated the superimposition of specific looks (symbolized by two crossing lines) and the fixated plan of the table. 1B: view of front webcam synchronized to the two other cameras to record infants' behavior, facial expressions and head orientation (infant with a Mini Bird Head tracker). 1C: infant's line of gaze was measured by computing the pupil-corneal reflection at a sampling rate of $50 \mathrm{~Hz}$.

Figure 2: Examples of images recorded by scene camera allowing to record infant's hands activity useful for the coding of hands activity. The superimposition of the fixed plane with the looks (intersection of horizontal and vertical black lines) on video recording scene plane gave indication of when infants looked at the hands.

Figure. 3: Calibration phase: 9 calibrations points were used. This most frequently used method provides robust and accurate data under most circumstances (a). A Flashing Ball was used to visually attract the subject: for each nine points, the flashing ball was put on a calibration point (examples in $\mathrm{b}$ and c). For each calibration point, when the infant looked at the ball and we had simultaneously a cross given by the eye-tracker indicating a gaze, another experimenter approved the calibration point and manually confirmed it on the computer. The target-object was placed on the table, on the right or on the left of the baby, inside the scene plane.

716 Figure 4. Proportion of time the left- and the right-hand remained stationary

717 Figure 5: Distribution of gazes (in \%) according to the hand tested.

718 Figure 6: Distribution of gazes (in \%) when the hand tested remained stationary according to the hand 719 tested.

Figure 7: Distribution of gazes (in \%) when the hand tested is moving according to the hand tested. 


\section{Ceiling camera}

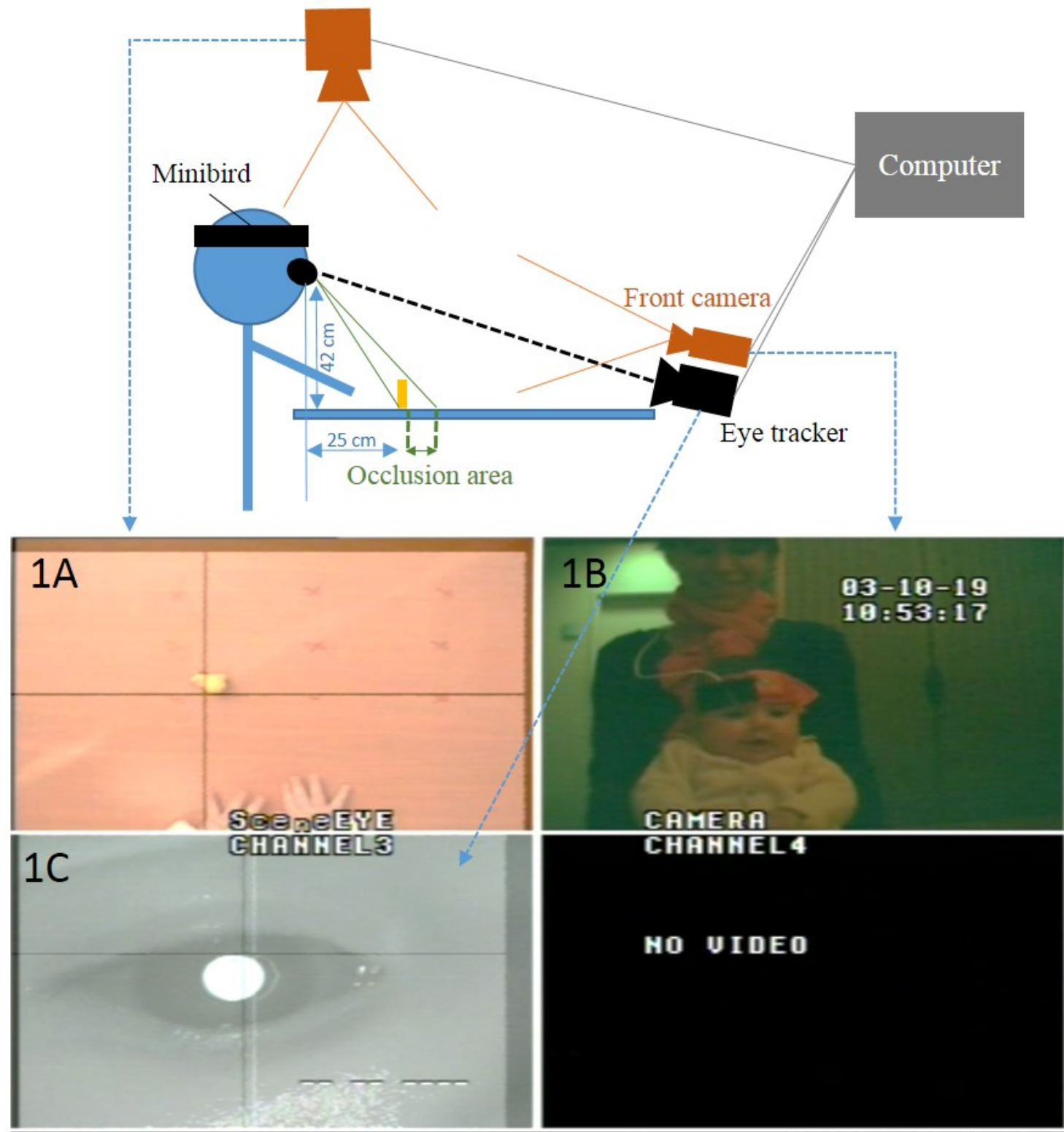


Calibration points

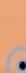

(a)

\section{OBJECT}

positions

\section{S@e日neEYE}

(b) 


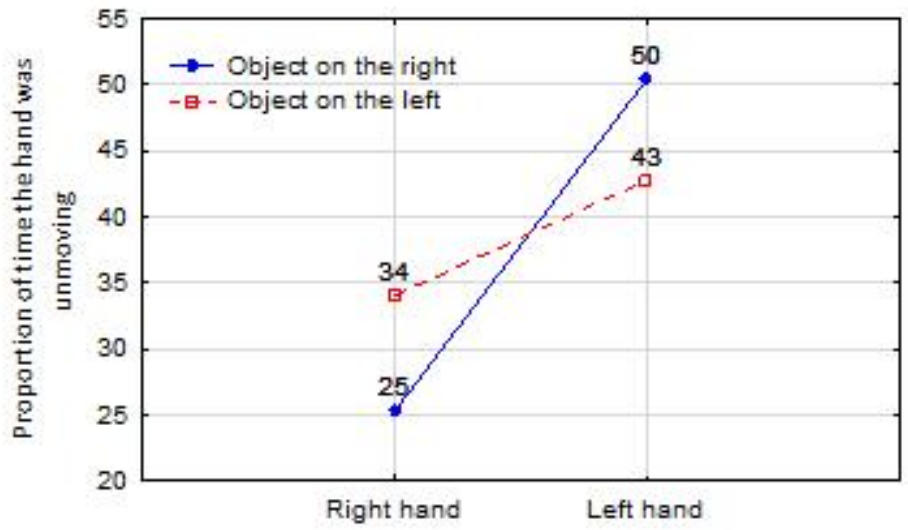


Right hand

Left hand

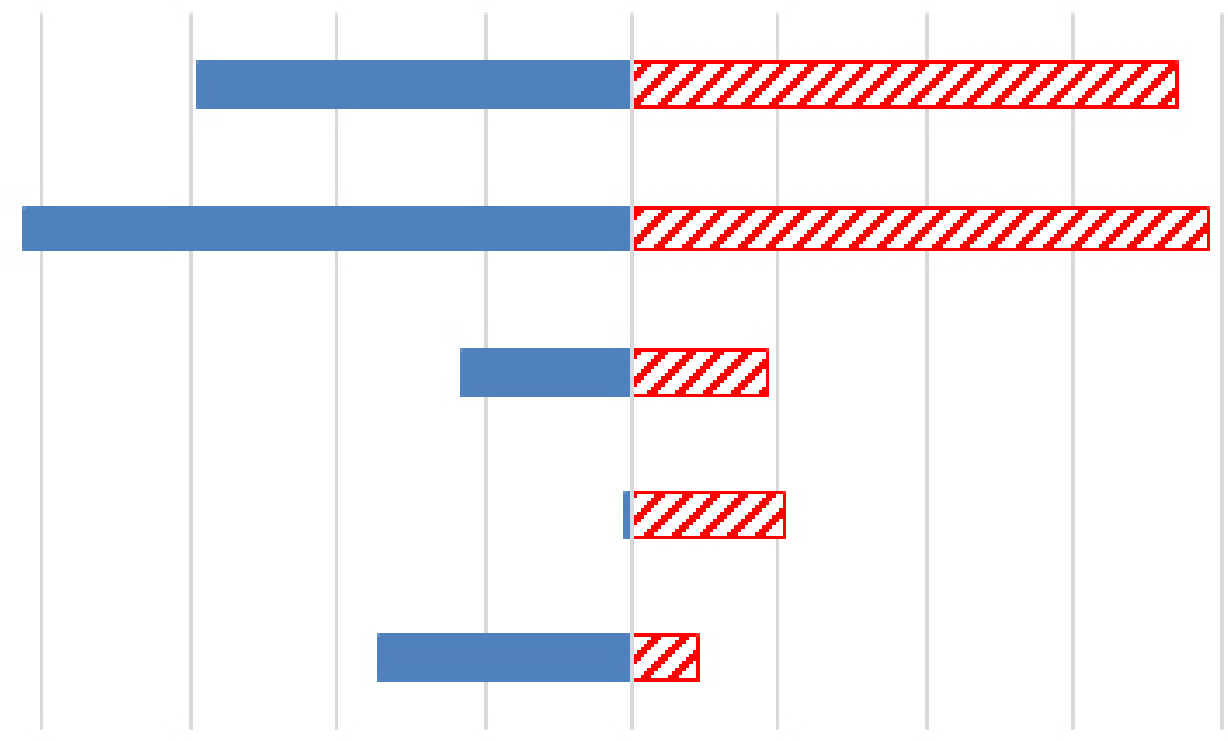

$\begin{array}{lllllllllll}50 \% & 40 \% & 30 \% & 20 \% & 10 \% & 0 \% & 10 \% & 20 \% & 30 \% & 40 \% & 50 \%\end{array}$

- Left hand reaching $\quad \nabla$ Right hand reaching 
Object

Around object

Table

Right hand

Left hand

$$
\begin{aligned}
& \begin{array}{lllllllllllll}
60 \% & 50 \% & 40 \% & 30 \% & 20 \% & 10 \% & 0 \% & 10 \% & 20 \% & 30 \% & 40 \% & 50 \%
\end{array} \\
& \text { - Left hand } \quad \square \text { Right hand }
\end{aligned}
$$




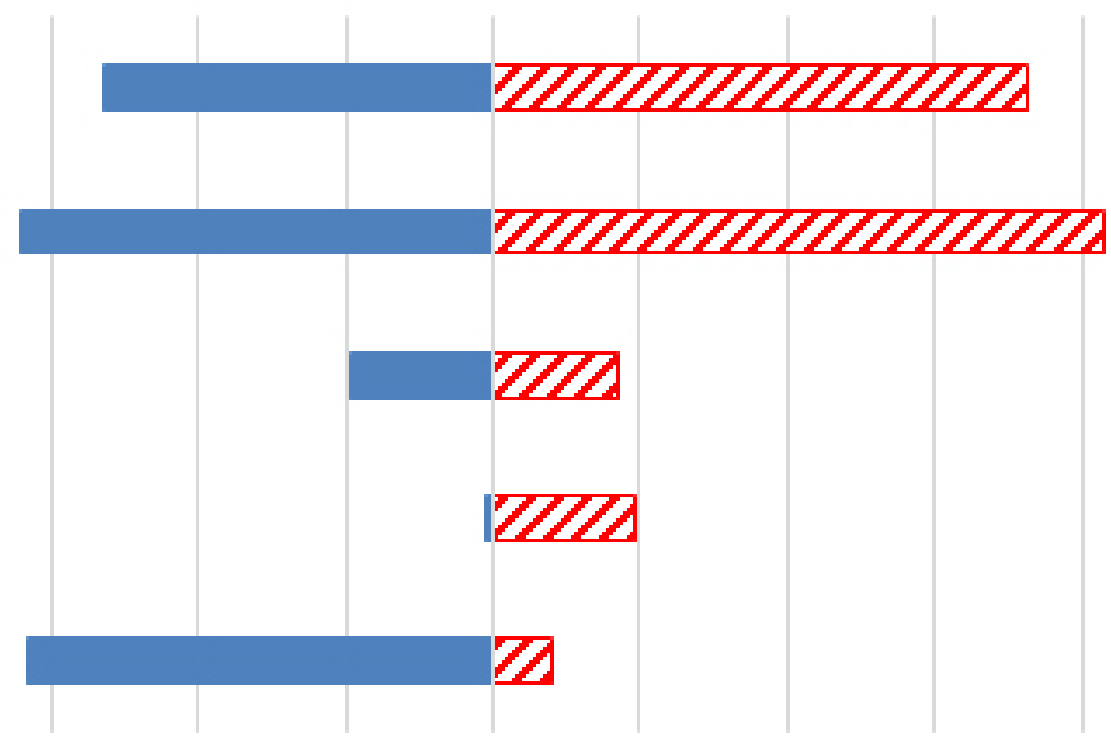

Right hand

Left hand

\section{Table}

$\begin{array}{lllllllllll}50 \% & 40 \% & 30 \% & 20 \% & 10 \% & 0 \% & 10 \% & 20 \% & 30 \% & 40 \% & 50 \%\end{array}$

- Left hand reaching $\quad \square$ Right hand reaching 